\title{
A New Multi-Sample EOS Model for the Gas Condensate Phase Behavior Analysis
}

\author{
A. Mehrabian ${ }^{1,2^{*}}$ and F. Crespo ${ }^{3}$ \\ 1 Center of Excellence in Energy Conversion, Mechanical Engineering Department, Sharif University of Technology, Tehran - Iran \\ 2 Department of Chemical and Petroleum Engineering, Sharif University of Technology, Tehran - Iran \\ 3 Mewbourne School of Petroleum and Geological Engineering, University of Oklahoma, Norman, Oklahoma - USA \\ e-mail: amin@ou.edu - freddy.crespo@ou.edu \\ * Corresponding author
}

\begin{abstract}
Résumé - Un nouveau modèle d'EOS multi-échantillon pour l'analyse de comportement de phase de condensat de gaz - Les équations d'état (EOS) sont largement utilisées pour prédire le comportement des phases des fluides de réservoir. Par rapport aux modèles classiques de corrélation, la précision des techniques de modélisation par EOS a permis une amélioration des prédictions des propriétés de ces fluides. Lorsque le pétrole brut ou les condensats de gaz ont été correctement caractérisés au moyen d'un nombre limité de tests de laboratoire, leur comportement PVT peut être facilement étudié dans différentes conditions. Dans cet article, le comportement PVT du condensat de gaz d'un réservoir dans le champ de gaz de South Pars en Iran a été modélisé en suivant les équations d'état à trois paramètres de Patel et Teja. La méthode de caractérisation multi-échantillons est utilisée pour obtenir un modèle cohérent pour le gaz rétrograde dans le réservoir entier. Les échantillons de fluide sont d'abord analysés dans un but de cohérence afin de découvrir d'éventuelles anomalies dans les propriétés du réservoir/fluide. Par la suite, les données cohérentes relatives aux fluides sont utilisées pour obtenir des paramètres pour le modèle EOS. Une procédure simplifiée d'agrégats avec une fraction à pseudo-composante, obtenue au moyen de la méthode de fractionnement de Pederson, est utilisée pour les échantillons afin de caractériser de façon unique le composant lourd de fluide du réservoir. Les résultats des tests de constante de composition et de diminution constante de volume ainsi que les pressions expérimentales de pointe de rosée sont utilisés pour le réglage des EOS. Les résultats ont démontré que l'utilisation du modèle EOS permet de très bonnes similitudes entre les propriétés PVT prédites avec les données obtenues expérimentalement. Ces résultats confirment l'utilité des réglages à l'aide d'EOS sur les propriétés des fractions lourdes quel que soit l'échantillon. Le modèle EOS développé pour ce site particulier peut être utilisé dans des études de simulation concernant les projets de récupération.
\end{abstract}

\footnotetext{
Abstract - A New Multi-Sample EOS Model for the Gas Condensate Phase Behavior Analysis Equations of State EOS are vastly being used to predict the phase behavior of reservoir fluids. The accuracy of EOS modeling technique over conventional correlation models would benefit an improved property prediction of these fluids. Once the crude oil or gas condensate fluid system has been probably characterized using limited laboratory tests, its PVT behavior under a variety of conditions can be easily studied. In this paper, the PVT behavior of gas condensate from a reservoir in South Pars retrograde gas field in Iran was modeled using the three-parameter Patel and Teja Equation of State. The multi-sample characterization method is used to arrive at one consistent model for retrograde gas in the whole reservoir. The fluid samples are first analyzed for consistency. To ensure that there is not any abnormal changes in fluid/reservoir properties, and then the consistent fluid data are used to obtain parameters for
} 
EOS model. A simplified lumping procedure along with a consistent $C_{12+}$ pseudo-component split using the Pederson splitting method is used for the samples in order to uniquely characterize the heavy fraction component of the reservoir fluid. The results of constant composition expansion and constant volume depletion laboratory tests as well as the experimental dew point pressures are used for EOS tuning. The results demonstrated a very good match of PVT properties predicted using the EOS model with experiment and laboratory tests for this field. These results confirm the usefulness of the EOS tuning on heavy fraction properties for all samples. The EOS model developed for this particular field may be used in simulation studies concerning recovery projects.

\section{NOMENCLATURE}

$\begin{array}{ll}A P D & \text { Average Perforation Depth } \\ M W & \text { Molecular Weight } \\ P & \text { Pressure } \\ P_{d} & \text { Dew point pressure } \\ P_{r} & \text { Reservoir pressure } \\ T & \text { Temperature } \\ V & \text { Volume } \\ Z & \text { Compressibility factor } \\ k_{i j} & \text { Binary interaction coefficient } \\ n & \text { Carbon number } \\ w & \text { Average weight fraction } \\ z & \text { Mole fraction }\end{array}$

\section{Greek symbols}

$\Delta \quad$ Tuning objective function

$\varphi \quad$ Fugacity

$\alpha, \beta$ Parameters defining Pederson splitting formula

$\gamma \quad$ Specific gravity

$\lambda$ Weighting factor

$\xi \quad$ Parameter in PT-EOS

\section{Subscripts}

c Critical property

$d \quad$ Dew point

$i, j \quad$ Component

$m \quad$ Mean property of the mixture

\section{Superscripts}

exp Experimental value

pred EOS predicted value

\section{INTRODUCTION}

In successful design of recovery processes for discovered reservoirs, proper knowledge about the phase behavior and other thermodynamic properties of the reservoir fluids would be of great importance. In this regards, considerable effort have been devoted to develop accurate models for the prediction of phase behavior and thermodynamic properties of petroleum fluids, which usually contain a variety of hydrocarbons and other organic and inorganic compounds. Equations of state have been traditionally used in volumetric and phase behavior modeling of reservoir fluids. These models have the advantage over PVT correlations that they would be valid for a wide variety of fluids from different reservoirs. Redlich and Kwong (1949) showed that a simple modification in the attractive term of the Van der Waals EOS would result in a significant improvement in the volumetric phase behavior of the vapors. They deduced their equation on the basis of the observation that if the system pressure grows infinitely, the molar volume of a substance would be reduced to 0.26 of the critical volume. A great improvement suggested by Soave (1972) was substitution of the attractive term of the RK-EOS with a more general parameter that depends on the reduced temperature and acentric factor of the substance. Later, Graboski and Daubert (1978) and Sim and Daubert (1980) suggested better correlations for dependency of the attractive parameter to acentric factor to improve the predictions of the vapor pressures of pure substances. The Equation of state introduced by Peng and Robinson (1976) has become one of the most widely used models for petroleum fluid properties prediction. They demonstrated that the performance of SRK-EOS in predicting the liquid phase specific gravity would be augmented by introducing an experimental parameter obtained by the analysis of the critical compressibility factor.

Numerous studies have attempted to improve the capabilities of EOSs. The chief progress in development of EOS modeling was the introduction of three parameter EOSs. The third parameter provides a better flexibility for prediction of critical compressibility factor and volumetric behavior of liquid phases (Danesh, 1998). Heyen (1983) introduced a modified PR-EOS in which a third parameter was included to achieve the real critical compressibility factor for various fluids. Kubic (1982) used a modified three parameter Martin Equation for calculation of vapor-liquid equilibrium. More elaborate equations of state were introduced later by other researchers. Shmidt and Wenzel (1980) utilized the acentric factor as the third parameter in their EOS while, Patel and Teja (1982) introduced a three parameter EOS with critical 
compressibility factor as the independent variable which may be obtained from the experiment. They suggested that a greater value for this parameter should be applied in the EOS in order to obtain reasonable results for prediction of specific gravities at extreme pressures.

The method of volume shift was first introduced by Peneloux et al. (1982) and Jhaveri and Youngren (1984) to improve the accuracy of SRK-EOS and PR-EOS. They also provided a correlation to define the volume shift for the heavy hydrocarbon components. Much improvement resulted from the introduction of parameters called Binary Interaction Coefficients, BICs, to better match the saturation pressure predictions. Slot-Petersen (1987) found the major characteristics for BICs. He provided the basis of a theory which describes the methods for calculating BICs. Groboski and Daubert (1978) urged that the use of BICs is not necessary in EOS modeling of hydrocarbon systems. However, Katz and Firooz-abadi (1978) proposed a fixed set of BICs for methane-hydrocarbon mixtures. Coats and Smart (1986) introduced the EOS tuning technique to enhance the performance of equations of state in predicting the experimental PVT data. They found that the critical properties of the heavy components, the parameter $\Omega$ for methane and BICs can be adjusted or "tuned" with available experimental data to obtain reasonable predictions. Pedersen et al. (1989) also found that the properties of heavy components may be used as the regression parameters during the EOS tuning process. Merril and Newly (1993) reported a systematic investigation into the most suitable data for the development of equations of state for petroleum reservoir fluids. Merril et al. (1994) presented a comparison between different EOS tuning techniques. Abrishami et al. (1997) suggested a tuning method of Peng-Robinson equation of state for simulation of compositional change in flue gas injection processes. The tuning involved the critical properties and acentric factor of heavy components, the $\Omega$ values of the equation of state, as well as the Binary Interaction Coefficients. They concluded in their work that completely different tunings were needed for a simple volumetric match or for the more complicated composition match.

Components with a carbon number higher than 6 are often grouped as a single component called heptanes-plus fraction or $\mathrm{C}_{7+}$ specially, in the absence of detailed analytical data. One can also group components with a higher carbon number. For the past two decades, proper characterization of heavy fractions encountered in nearly all reservoir fluids has been the major problem in PVT modeling. Adequate characterization of the heavy fractions is critical due to its profound effect on the PVT properties and the phase equilibria of a hydrocarbon system. Especially, volumetric and phase behavior of the gas condensate.

The splitting technique is one of the most widely accepted methods for reducing errors with $\mathrm{C}_{7+}$ characterization. This technique consists on breaking the $\mathrm{C}_{7+}$ into a finite number of fractions called pseudo components. Katz (1983) developed a simple graphical method for $\mathrm{C}_{7+}$ splitting. His method was based on the extended analysis on the behavior of different condensate systems. Pedersen et al. (1982) offered an exponential relationship between mole fraction and Carbon number of the split fractions. However, Whitson et al. (1988) used a more elaborate gamma distribution function to describe such relationship. Ahmed et al. (1985) used the molecular weight and the mole fraction of the heavier fractions as the input parameters for their split method. A simple recursive relationship for obtaining the molecular weight of each pseudo-component was used in their model. Riazi (1997) suggested a two parameter distribution model. His results were in excellent agreement with the laboratory data.

Often, a large number of pseudo-components is sufficient to obtain satisfactory predictions of the PVT behavior. However, the maximum number of components that can be used in compositional models are limited due to cost and computing time. Therefore, the original components have to be grouped or lumped into a smaller number of pseudo-components. Several methods to use this technique without losing the predicting power of the equation of state have been presented (Lee et al., 1979; Whitson, 1980; Hong, 1982).

In this paper, the PVT behavior of gas condensate system produced from different production wells in South Pars gas field located in Iran is modeled based on the Patel and Teja Equation of state. A multi-well characterization method is utilized along with an extensive validation with the accurate laboratory data. A simplified lumping procedure along with a consistent $\mathrm{C}_{12+}$ pseudo-component split using the Pederson splitting method is used for the samples in order to uniquely characterize the heavy fraction component of the reservoir fluid. The Constant Volume Depletion (CVD) and Constant Composition Expansion (CCE) tests are simulated with the tuned equation of state. To examine the capability of suggested EOS model and regression scheme in PVT analysis of gas condensate systems, simulated separator test results are compared with some simulation results based on conventional EOS modeling methods.

\section{THE THREE-PARAMETER PT-EOS}

The Patel and Teja equation of state, PT-EOS (1982), is used in this study to model the PVT behavior of several gas condensate samples. Their equation may be written as follows:

$$
P=\frac{R T}{V-b}-\frac{a}{V^{2}-(b+c) V-b c}
$$

where, the following conditions must hold for Equation (1):

$$
\frac{\partial P}{\partial V_{T_{c}}}=0
$$




$$
\begin{aligned}
& \frac{\partial^{2} P}{\partial^{2} V_{T_{c}}}=0 \\
& \frac{P_{c} V_{c}}{R T_{c}}=\xi_{c}
\end{aligned}
$$

Patel and Teja urged that the third parameter $c$ in the equation will result in the arbitrary selection of the experimental parameter $\xi_{c}$. Applying (2), (3) and (4) in (1) yields the following equations for the parameters of the EOS:

$$
\begin{gathered}
a=\Omega_{a} \frac{R^{2} T_{c}^{2}}{P_{c}}\left[1+m\left(1-T_{r}^{0.5}\right)\right]^{2} \\
b=\Omega_{b} \frac{R T_{c}}{P_{c}} \\
c=\Omega_{c} \frac{R T_{c}}{P_{c}}
\end{gathered}
$$

where:

$$
\begin{gathered}
\Omega_{c}=1-3 \xi_{c} \\
\Omega_{a}=3 \xi_{c}^{2}+3\left(1-2 \xi_{c}\right)+\Omega_{b}^{2}+\left(1-3 \xi_{c}\right)
\end{gathered}
$$

and, $\Omega_{b}$ is the smallest positive root of the following equation:

$$
\Omega_{b}^{2}+\left(2-3 \xi_{c}\right) \Omega_{b}^{2}+3 \xi_{c}^{2} \Omega_{b}-\xi_{c}^{2}=0
$$

For hydrocarbon components the following correlations are suggested for the parameters $m$ and $\xi_{c}$ in terms of the acentric factor (Ahmed, 1989):

$$
\begin{gathered}
m=0.452413+1.309982 \omega-0.295937 \omega^{2} \\
\xi_{c}=0.329032-0.0767992 \omega+0.0211947 \omega^{2}
\end{gathered}
$$

The random quadratic mixing rules are selected for the mixtures as follows:

$$
\begin{gathered}
a_{m}=\sum_{i} \sum_{j}\left[x_{i} x_{j}\left(a_{i} a_{j}\right)^{0.5}\left(1-k_{i j}\right)\right] \\
b_{m}=\sum_{i}\left(x_{i} b_{i}\right) \\
c_{m}=\sum_{i}\left(x_{i} c_{i}\right)
\end{gathered}
$$

where, $x$ denotes the mole fraction of component $i$ or $j$. The $\mathrm{BICs}, k_{i j}$, are determined from the suggested values given by Danesh (1998) for PT-EOS. Equation (1) may be rewritten in terms of the compressibility factor $Z$, as the following dimensionless form:

$$
\begin{gathered}
Z^{3}+(C-1) Z^{2}+\left(A-2 B C-B-C-B^{2}\right) Z \\
+\left(B C+B^{2} C-A B\right)=0
\end{gathered}
$$

where:

$$
\begin{gathered}
A=\frac{a_{m} P}{(R T)^{2}} \\
B=\frac{b_{m} P}{(R T)} \\
C=\frac{c_{m} P}{(R T)}
\end{gathered}
$$

The predicting model is used for phase equilibrium calculations as well as the volumetric properties for all consistent samples. The phase fugacities obtained from the EOS may be calculated from the following equation (see $E q$. 20), where:

$$
\begin{gathered}
\psi_{i}=\sum_{i}\left[x_{i}\left(a_{i} a_{j}\right)^{0.5}\left(1-k_{i j}\right)\right] \\
Q=Z+0.5(B+C) \\
d=\left[B C+0.25(B+C)^{2}\right]^{0.5}
\end{gathered}
$$

The saturation pressure, compressibility data and volumetric gas liquid equilibrium results from the laboratory test at various pressure steps are used for tuning of the equation of state.

\section{EXPERIMENTAL DATA}

The experimental data used in this study includes a complete group of PVT laboratory data for five gas condensate samples obtained from South Pars gas field located in Iran. The information consists of reservoir fluid compositional analysis up to $\mathrm{C}_{12+}$ for three samples (Taken from SP12 and SP13 wells) and up to $\mathrm{C}_{26+}$ for two samples (Taken from SP7 well).

A complete set of Constant Composition Expansion (CCE) and Constant Volume Depletion (CVD) tests as well as separator data for all samples are provided in this study.

$$
\begin{aligned}
& \ln \left(\varphi_{i}\right)=-\ln (Z-B) \\
& +\left[\frac{b_{i}}{Z-B}-\frac{\psi_{i}}{R T d} \ln \left(\frac{Q+d}{Q-d}\right)+0.5 A\left(\frac{Q+d}{Q-d}\right)+0.125 A\left[c_{i}(3 B+C)+b_{i}(3 C+B)\right]\left\{\ln \left(\frac{Q+d}{Q-d}\right)-\frac{2 Q d}{Q^{2}-d^{2}}\right\}\right]\left(\frac{P}{R T}\right)
\end{aligned}
$$


The reservoir characteristics and well information as well as the chemical composition of the samples for the field under consideration are provided in Table 1 . The compositional data of samples 4 and 5 are adjusted and reported up to $\mathrm{C}_{12+}$ as the other samples using the Hoang lumping method which is explained in Section 3. The general properties of these samples are presented in Table 2.

TABLE 1

Reservoir and composition analysis of the gas condensate samples

\begin{tabular}{|c|c|c|c|c|c|}
\hline \multicolumn{6}{|c|}{ Chemical composition of samples in $\%$ mole } \\
\hline Sample & 1 & 2 & 3 & 4 & 5 \\
\hline Well & SP12 & SP13 & SP13 & SP7 & SP7 \\
\hline Formation & $\mathrm{k} 4$ & k4 & $\mathrm{K} 2+\mathrm{K} 3$ & $\mathrm{k} 4$ & $\mathrm{k} 3$ \\
\hline $\mathrm{N}_{2}$ & 2.91 & 3.49 & 3.05 & 3.21 & 3.302 \\
\hline $\mathrm{CO}_{2}$ & 2.12 & 2.29 & 2.02 & 1.992 & 2.026 \\
\hline $\mathrm{H}_{2} \mathrm{~S}$ & 0.15 & 0.13 & 0.18 & 0.237 & 0.343 \\
\hline $\mathrm{C}_{1}$ & 82.49 & 82.29 & 82.86 & 81.467 & 81.418 \\
\hline $\mathrm{C}_{2}$ & 5.39 & 5.01 & 5.04 & 5.268 & 5.13 \\
\hline $\mathrm{C}_{3}$ & 1.95 & 1.79 & 1.79 & 2.066 & 1.959 \\
\hline $\mathrm{iC}_{4}$ & 0.46 & 0.43 & 0.43 & 0.475 & 0.442 \\
\hline $\mathrm{nC}_{4}$ & 0.76 & 0.72 & 0.7 & 0.828 & 0.769 \\
\hline $\mathrm{iC}_{5}$ & 0.38 & 0.37 & 0.35 & 0.396 & 0.368 \\
\hline $\mathrm{nC}_{5}$ & 0.32 & 0.32 & 0.31 & 0.485 & 0.356 \\
\hline $\mathrm{C}_{6}$ & 0.39 & 0.52 & 0.48 & 0.879 & 0.799 \\
\hline $\mathrm{C}_{7}$ & 0.56 & 0.63 & 0.61 & 0.561 & 0.674 \\
\hline $\mathrm{C}_{8}$ & 0.57 & 0.62 & 0.62 & 0.467 & 0.531 \\
\hline $\mathrm{C}_{9}$ & 0.44 & 0.4 & 0.41 & 0.402 & 0.417 \\
\hline $\mathrm{C}_{10}$ & 0.35 & 0.31 & 0.33 & 0.335 & 0.343 \\
\hline $\mathrm{C}_{11}$ & 0.23 & 0.23 & 0.24 & 0.224 & 0.238 \\
\hline $\mathrm{C}_{12+}$ & 0.53 & 0.45 & 0.58 & 0.71 & 0.89 \\
\hline
\end{tabular}

TABLE 2

General properties the gas condensate samples

\begin{tabular}{c|c|c|c|c|c}
\hline \multicolumn{6}{c}{ Reservoir and well characteristics } \\
\hline Sample & 1 & 2 & 3 & 4 & 5 \\
\hline Well & $\mathrm{SP} 12$ & $\mathrm{SP} 13$ & $\mathrm{SP} 13$ & $\mathrm{SP7}$ & $\mathrm{SP7}$ \\
\hline Formation & $\mathrm{k} 4$ & $\mathrm{k} 4$ & $\mathrm{~K} 2+\mathrm{K} 3$ & $\mathrm{k} 4$ & $\mathrm{k} 3$ \\
\hline Molar mass $(\mathrm{g} / \mathrm{mole})$ & 22.75 & 22.62 & 22.93 & 22.83 & 22.92 \\
\hline $\mathrm{P}_{\text {res }}(\mathrm{psia})$ & 5321 & 5370 & 5308 & 5305 & 5236.1 \\
\hline $\mathrm{P}_{\mathrm{d}}(\mathrm{psia})$ & 5250 & 4950 & 5330 & 5165 & 5236.1 \\
\hline $\mathrm{T}_{\text {cr }}\left({ }^{\circ} \mathrm{F}\right)$ & -73.5 & -74.3 & -74.8 & -71.3 & -72.4 \\
\hline $\mathrm{P}_{\text {cr }}(\mathrm{psi})$ & 660.7 & 660.1 & 659.6 & 658.4 & 658.3 \\
\hline Res. temp. $\left({ }^{\circ} \mathrm{F}\right)$ & 216 & 221 & 213 & 213.6 & 207.1 \\
\hline
\end{tabular}

As demonstrated in Table 2, samples are taken from different formations in the gas field. Figure 1 represents the plots of reservoir temperature and pressure variation as well as the heavy fraction composition gradient with depth. These plots are provided in order to ensure that no abnormal changes in reservoir characteristics among different formations are present for the field under consideration. Figures 1a and $1 \mathrm{~b}$ show that the uniform temperature and pressure gradients with depth may be considered. Also, Figure 1c shows all samples follow a linear trend with decreasing in $\mathrm{C}_{7+}$ mole fraction with depth. These plots indicate that fluid samples taken from all wells are in well communication with each other and they represent the properties of reservoir under consideration. Hence, the EOS model could be applied based on data from all samples.
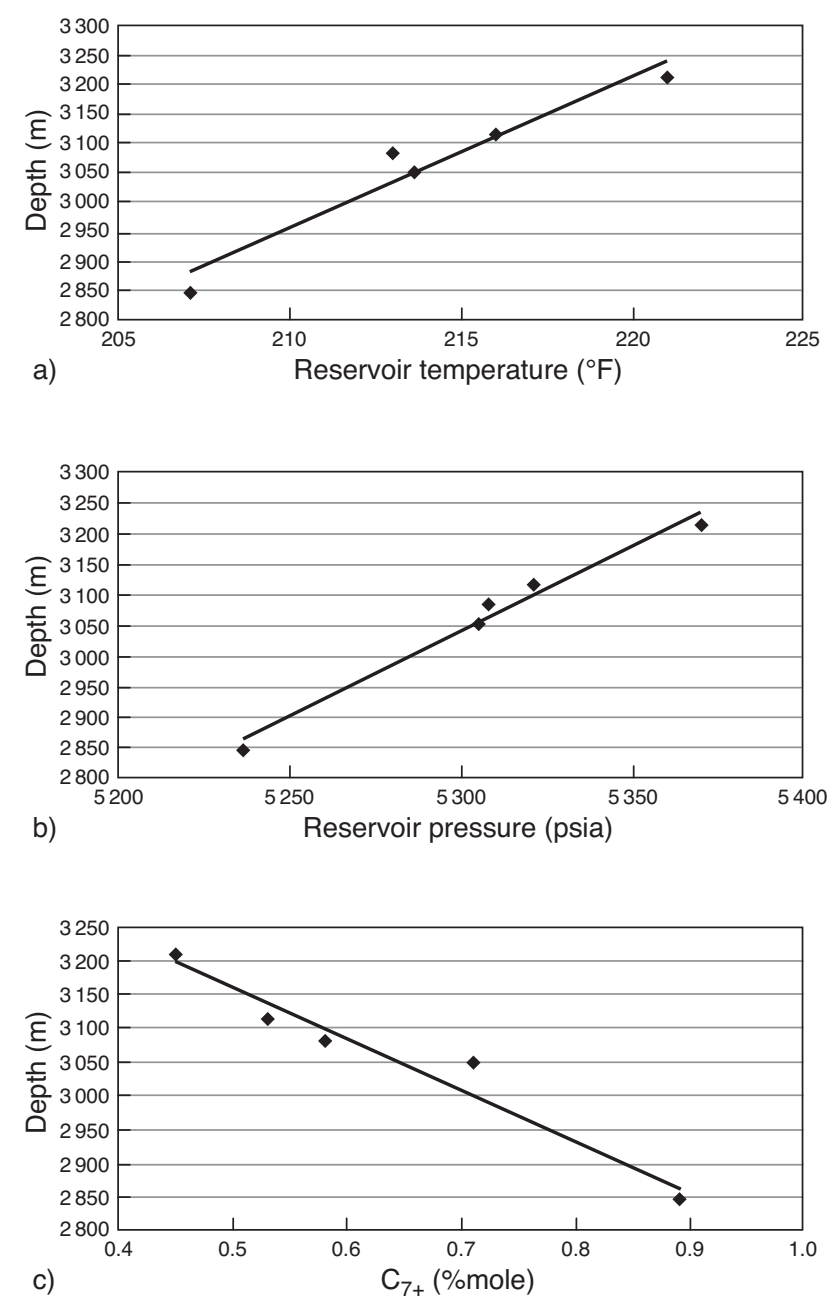

Figure 1

a) Reservoir temperature variation with depth. b) Reservoir pressure with depth. c) Variation of mole fraction of $\mathrm{C}_{7+}$ pseudo-component with depth. 


\section{GROUPING, SPLITTING AND EOS TUNING}

Compositional analysis of samples 1, 2 and 3 (up to $\mathrm{C}_{12+}$ ), and samples 4 and $5\left(\mathrm{C}_{26+}\right)$ are different. In order to unify their compositional properties, a lumping technique provided by Hong (1982) is applied on samples 4 and 5 taken from the well SP7. Hong suggested that in characterization of the heavy fraction, the average weight fraction of the components $w$ is the best parameter for introducing the mixing rules. The expressions to obtain the molecular weight $M W$ and the specific gravity $\gamma$ of the lumped components, may be written as follows:

$$
\begin{aligned}
M W_{L} & =\sum w_{i} M W_{i} \\
\gamma_{L} & =\sum w_{i} \gamma_{i}
\end{aligned}
$$

where:

$$
w_{i}=\frac{z_{i} M W_{i}}{\sum z_{i} M W_{i}}
$$

Equations (24) and (25) are applied on samples 4 and 5, in order to lump the $\mathrm{C}_{12}-\mathrm{C}_{26+}$ components into a lumped $\mathrm{C}_{12+}$ component. This makes all samples to have a similar lumped pseudo-component, $\mathrm{C}_{12+}$. The reported $\mathrm{C}_{12+}$ mole fractions in Table 1 correspond to their post-lumping values.

In the next step, the plus fraction is split into five pseudocomponents $\left(\mathrm{C}_{12}-\mathrm{C}_{16+}\right)$ in order to characterize its properties. The split pseudo-components of each of the five samples must have the same molecular weight, whereas their corresponding mole fraction varies. A heavy fraction characterization technique introduced by Pedersen et al. (1982) is utilized in this study. Their model provided an exponential relationship between the mole fraction $z_{n}$ and the Carbon number of a specific component $n$. Such relationship may be written as:

$$
z_{n}=\exp \left[\frac{(n-\alpha)}{\beta}\right]
$$

The splitting parameters $\alpha$ and $\beta$ can be obtained by a least-squares fit applied on the molar distribution of the lighter sample components. Once the constant parameters are determined, the mole fraction of the split fractions can be found using Equation (27). The critical properties of pseudo components are estimated from the vigorous generalized Riazi and Daubert correlations (1987).

To improve the capabilities of the EOS model in prediction of phase equilibrium and volumetric behavior, a number of regression schemes are considered to choose among the most significant parameters appropriate for tuning. The capability of EOS in predicting the phase volume of gas condensate systems, particularly within the retrograde region is generally inferior to that of gas-oil systems. Such a behavior could be predicted as less accuracy is expected in modeling the behavior of heavy compounds, which dominate the liquid drop out phase. Hence, one scheme is to modify to plus fraction properties such as the molecular weight of heavy fraction and the splitting parameters, $\alpha$ and $\beta$. Almehaideb et al. (2000) reported a very successful EOS tuning on a crude oil multi-sample with the $\mathrm{C}_{7+}$ molecular weight and splitting parameters taken as regression variables. In this study, using a similar approach, these parameters are used for EOS tuning to match the experimental dew point and laboratory test data.

For tuning procedure, an objective function $\Delta$ is selected as the sum of weighted square deviations:

$$
\Delta=\sum_{j=1}^{N_{\text {data }}}\left[\lambda_{i}\left(\frac{\Lambda_{j}^{\text {pred }}-\Lambda_{j}^{\text {exp }}}{\Lambda_{j}^{\exp }}\right)\right]^{2}
$$

where, each element of the objective function expresses the weighted difference between the predicted and experimental values, $\Lambda^{\text {pred }}, \Lambda^{e x p}$, respectively, and $N_{\text {data }}$ expresses the number of measured data points to be fitted. The optimum values of variables are obtained by minimizing the function $\Delta$. A modification of Levenberg-Marquardt method proposed by Marquardt (1963) is used in this study to minimize the function $\Delta$.

\section{RESULTS AND DISCUSSION}

Danesh (1998) reported that the error in predicting the retrograde liquid volume below the dew point can be reduced markedly by tuning EOS to match the dew point. In this study, the laboratory saturation pressure data for the samples under consideration are available. The EOS model with default parameters is primarily utilized to calculate the phase equilibrium fugacities at saturation pressure using Equation (19). An improved successive substitution algorithm proposed by Xu et al. (1992) is used to obtain the saturation pressure of each sample. Then, the EOS model is tuned for heavy fraction properties as described in previous section. Table 3 is a comparison between the experimental dew points and the corresponding values predicted by EOS before and after tuning. The Absolute Average Deviation AAD is defined as follows:

$$
\% A A D=\frac{1}{N} \sum_{i}^{n}\left|\left(\frac{P_{d}^{\text {exp }}-P_{d}^{\text {pred }}}{P_{d}^{\exp }}\right)\right|
$$

where, $N=5$ denotes the number of samples under consideration. It is evident that considerable improvement in saturation pressure estimation by EOS has been achieved via regression of $\mathrm{C}_{12+}$ properties.

The initial and final values of the molecular weight of $\mathrm{C}_{12+}$, and the splitting parameters, $\alpha$ and $\beta$, for each sample are illustrated in Table 4. 
TABLE 3

Effect of EOS tuning on predicted dew point pressures using PT-EOS model

\begin{tabular}{c|c|c|c|c}
\hline $\begin{array}{c}\text { Well } \\
\text { (Formation) }\end{array}$ & $T\left({ }^{\circ} \mathrm{F}\right)$ & $\begin{array}{c}\text { Experimental } \\
\text { dew point } \\
\text { pressure (psia) }\end{array}$ & \multicolumn{2}{|c}{$\begin{array}{c}\text { Predicted dew point } \\
\text { pressure (psia) }\end{array}$} \\
\hline & & & Before tuning & After tuning \\
\hline SP12 (k4) & 216 & 5250 & 5932 & 5264 \\
\hline SP13 (k4) & 221 & 4950 & 5341 & 4991 \\
\hline SP13 (K2+K3) & 213 & 5330 & 5849 & 5383 \\
\hline SP7 (k4) & 213.6 & 5165 & 5711 & 5169 \\
\hline SP7 (k3) & 207.1 & 5236 & 5388 & 5252 \\
\hline$\% A A D$ & & & 8.01 & 0.494 \\
\hline
\end{tabular}

TABLE 4

Regression parameters and corresponding values

\begin{tabular}{c|c|c|c|c|c|c}
\hline \multirow{2}{*}{$\begin{array}{c}\text { Well } \\
\text { (Formation) }\end{array}$} & \multicolumn{2}{|c|}{$\mathrm{MW}_{\mathrm{C} 12+}$} & \multicolumn{2}{c|}{$\alpha$} & \multicolumn{2}{c}{$\beta$} \\
\cline { 2 - 7 } & $\begin{array}{c}\text { Initial } \\
\text { value }\end{array}$ & $\begin{array}{c}\text { Final } \\
\text { value }\end{array}$ & $\begin{array}{c}\text { Initial } \\
\text { value }\end{array}$ & $\begin{array}{c}\text { Final } \\
\text { value }\end{array}$ & $\begin{array}{c}\text { Initial } \\
\text { value }\end{array}$ & $\begin{array}{c}\text { Final } \\
\text { value }\end{array}$ \\
\hline SP12 (k4) & 223.13 & 247.64 & 2.643 & 2.730 & -0.3724 & -0.3822 \\
\hline SP13 (k4) & 279.82 & 286.09 & 2.598 & 2.582 & -0.3624 & -0.3621 \\
\hline SP13 (K2+K3) & 250.33 & 295.33 & 2.610 & 2.725 & -0.3622 & -0.3762 \\
\hline SP7 (k4) & 223.14 & 228.51 & 2.634 & 2.621 & -0.3714 & -0.3709 \\
\hline SP7 (k3) & 224.4 & 231.66 & 2.617 & 2.6842 & -0.3675 & -0.3697 \\
\hline Average \%Diff. & \multicolumn{2}{|c}{6.56} & \multicolumn{2}{c|}{2.28} & 1.46 \\
\hline
\end{tabular}

An immediate observation of Table 4 data is that very close values for parameters $\alpha$ and $\beta$ are for the fluids samples are predicted. This is in agreement with the assumption that fluid samples are coming from well-communicated formations.

Figure 2 displays the results of Constant Composition Expansion tests on the sample taken from W7 well in k3 formation. Figure 2a displays the produced liquid volume due to retrograde expansion in the cell. The values are based on hydrocarbon pore volume percentage, \%HPV. Experimental CCE data are shown by points in the charts.

In Figure $2 b$, the total volume of the fluid in the cell is plotted vs pressure. The values are calculated relative to the fluid volume at dew point. The dotted and solid lines in each chart are representatives of EOS simulated results, previous to tuning and after tuning, respectively. A significant improvement is evident in the prediction capability of EOS model by tuning. This improvement is essentially observed in the predicted values of the generated liquid volumes. These findings indicate the significance of the proper selection of regression parameters described previously.
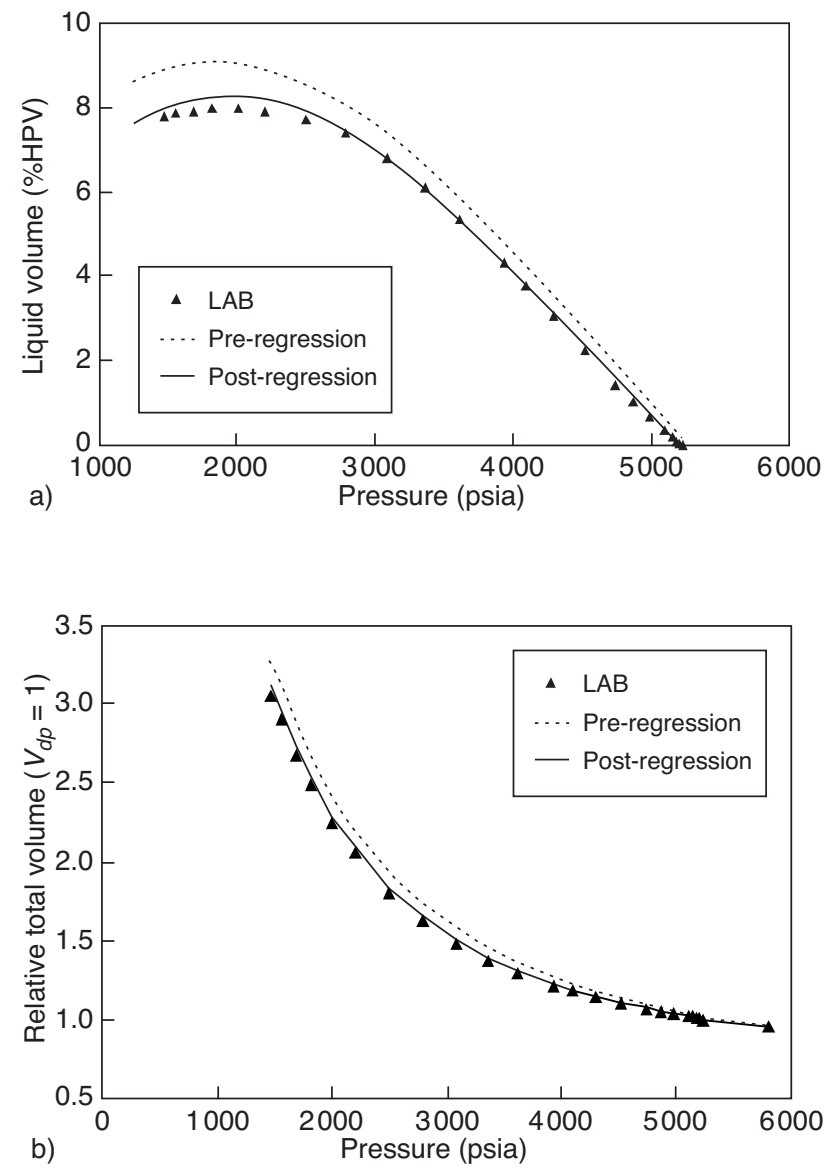

Figure 2

CCE test results on W7-k3 sample: a) liquid volume $v s$ pressure; b) relative total volume $v s$ pressure.

The results of Constant Volume Depletion tests are illustrated in Figure 3. The experimental data as well as the simulated curves are shown on each chart. Figure 3a represents the compressibility factor of the produced gas while, the retrograde liquid volume based on \%HPV is plotted $v s$ pressure in Figure $3 \mathrm{~b}$. It should be noted that both curves in Figure $3 \mathrm{~b}$ approach the experimental data in the vaporizing region. This phenomenon indicates the EOS model results would be superior where the system behaves oil-like.

In order to demonstrate the efficiency of the suggested EOS model and regression methodology in analyzing the phase behavior of gas condensate systems, a summary of separator test results driven on $\mathrm{W} 7-\mathrm{k} 4$ sample along with the simulated results based on this study (simulation\#1) is shown in Table 5. Figures $4 \mathrm{a}$ and $4 \mathrm{~b}$ show the results of simulating gas deviation factor and liquid volume of CVD test for SP12 sample, respectively. The reported results of a PVT simulation (PVT SIM V2) using SRK-EOS and with a conventional 

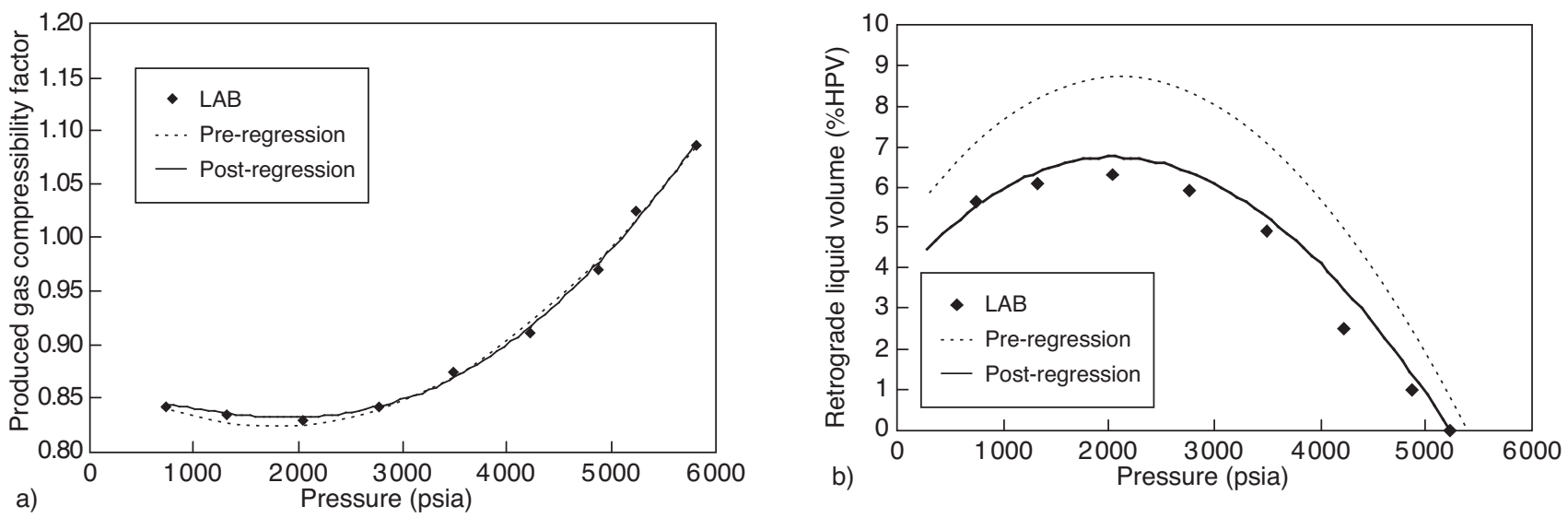

Figure 3

CVD test results on W7-k3 sample: a) produced gas compressibility factor $v s$ pressure; b) retrograde liquid volume $v s$ pressure.
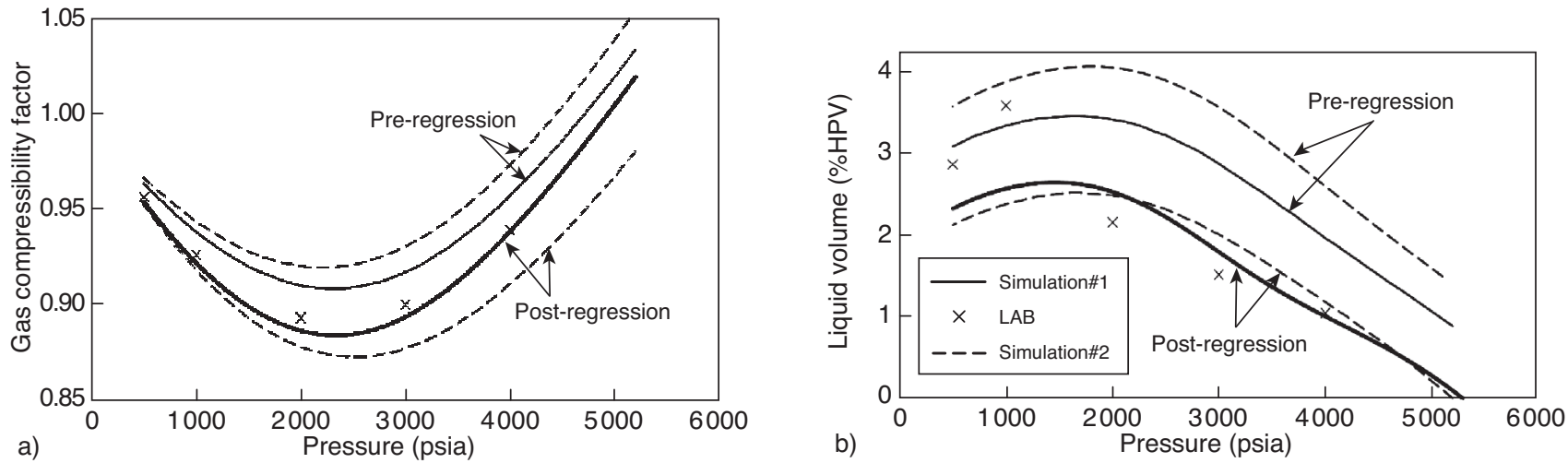

Figure 4

CVD test results on SP12-k4 sample, comparison of PT and SRK EOS: a) gas deviation factor $v s$ pressure; b) liquid volume $v s$ pressure.

TABLE 5

Separator test data with simulation results based on two different schemes

\begin{tabular}{|c|c|c|c|c|c|c|c|c|c|c|c|}
\hline \multicolumn{3}{|c|}{ Separator conditions } & \multicolumn{5}{|c|}{ Gas liquid ratio (scf/bbl) } & \multicolumn{4}{|c|}{ Separator gas deviation factor } \\
\hline $\begin{array}{c}\text { Pressure } \\
\text { (psia) }\end{array}$ & $\begin{array}{l}\text { Temp. } \\
\left({ }^{\circ} \mathrm{F}\right)\end{array}$ & Exp. & $\begin{array}{c}\text { Simulation \#1 } \\
\text { Post-reg. }\end{array}$ & $\% \mathrm{AD}$ & $\begin{array}{c}\text { Simulation \#2 } \\
\text { Post-reg. }\end{array}$ & $\% \mathrm{AD}$ & Exp. & $\begin{array}{c}\text { Simulation\#1 } \\
\text { Post-reg. }\end{array}$ & $\% \mathrm{AD}$ & $\begin{array}{c}\text { Simulation\#2 } \\
\text { Post-reg. }\end{array}$ & $\% \mathrm{AD}$ \\
\hline 2649.1 & 194 & 20178 & 19791 & 1.92 & 20764 & 2.90 & 0.864 & 0.8733 & 1.08 & 0.8983 & 2.86 \\
\hline 14.5 & 59 & 640.11 & 632.6 & 1.17 & 672.3 & 5.03 & 0.8542 & 0.8636 & 1.10 & 0.8887 & 2.91 \\
\hline$\%$ AAD & & & & 1.55 & & 3.97 & & & 1.09 & & 2.88 \\
\hline
\end{tabular}

tuning scheme (simulation\#2) are provided for comparison in Table 5 and Figure 4. A large set of regression parameters including critical properties $\left(P_{c}, T_{c}\right)$, the acentric factors and Peneloux correction factors of all components was considered in second scheme. The comparison between \%AAD of the two simulation schemes show the effectiveness of using three parameter EOS and regression based on heavy fraction molecular weight and splitting properties. 


\section{CONCLUSION}

In this paper, the gas condensate phase behavior from multiple wells was studied using a three parameter EOS model. The use of the three-parameter PT-EOS along with splitting and regression on heavy fraction properties provided a unique description for the whole reservoir fluid. Findings of aforementioned studies indicate the robustness of the EOS modeling methodology used in this study. This approach would only perform regression on the properties which are not measured accurately in laboratory. Another advantage of the suggested methodology is that the regression on minimal variables for tuning purposes would minimize the program runtime considerably. However, the quality of laboratory data including dew point pressures and volumetric properties of condensate phase appear to be crucial in the successful tuning task.

\section{ACKNOWLEDGMENT}

The Pars Oil \& Gas Company (POGC) is appreciatively acknowledged for making the PVT data used in this study available for the authors.

\section{REFERENCES}

Abrishami Y., Hatamian H., Dawe R.A. (1997) Tuning of PengRobinson Equation of State for Simulation of Compositional Change in Flue Gas Injection Processes, J. Fluid Phase Equilibria 139, 219-254.

Ahmed T. (1989) Hydrocarbon Phase Behavior, Gulf Publishing, Houston.

Ahmed T., Cady G., Story A. (1985) A Generalized Correlation for Characterizing the Hydrocarbon Heavy Fractions, SPE paper 14266 , 60th SPE Annual Conference, Las Vegas, USA, September 22-25.

Almehaideb R.A., Al-Khanbashi A.S., Abdulkarim M., Maher A.A. (2000) EOS Tuning to Model Full-field Crude Oil Properties Using Multiple Well Fluid PVT Analysis, J. Petrol. Sci. Eng. 26, 291-300. Coats K.H., Smart G.T. (1986) Application of a Regression-Based EOS PVT Program to Laboratory Data, SPE Reserv. Eng. 1, 3, 277-299.

Danesh A. (1998) PVT and Phase Behavior of Petroleum Reservoir Fluids, Elsevier science, Netherlands.

Graboski M.S., Daubert T.E. (1978) A Modified Soave Equation of State for Phase Equilibrium Calculations 1-Hydrocarbon Systems, Ind.Eng. Chem. Process Des. Dev. 17, 4, 443-448.

Heyen G. (1983) A Cubic Equation of State with Extended Range of Application, Proc. 2nd World Congress Chem. Eng., Montreal, Canada, October 4-9, pp. 41-46.

Hong K.C. (1982) Lumped Component Characterization of Crude Oils for Compositional Simulation, SPE/DOE paper 10691, 3rd Joint Symposium on EOR, Tulsa, Oklahoma, April 4-7.

Jhaveri B.S., Youngren G.K. (1984) Three Parameter Modification of the Peng-Robinson Equation of State to Improve Volumetric Predictions, SPE paper 13118, 59th SPE Annual Technical Congress, Houston, USA.
Katz D.L. (1983) Overview of Phase Behavior of Oil and Gas Production, J. Petrol. Technol.35, 6, 1205-1214.

Katz D.L., Firoozabadi A. (1978) Predicting Phase Behavior of Condensate/Crude-Oil Systems Using Methane Interaction Coefficients, J. Petrol. Technol. 30, 11, 1649-1655.

Kubic W.L.J. (1982) A Modification of the Martin Equation of State for Calculating Vapor-Liquid Equilibria, J. Fluid Phase Equilibria 9, 1, 79-97.

Lee S. et al. (1979) Experimental and Theoretical Studies on the Fluid Properties Required for Simulation of Thermal Processes, SPE paper 8393, presented at the SPE 54th Annual Technical Conference, Las Vegas, NV, September 23-26.

Merrill R.C., Hartman K.J., Creek J.L. (1994) A Comparison of Equation of State Tuning Methods, SPE paper 28589, SPE 69th Annual Technical Conference and Exhibition, New Orleans, USA.

Merrill R.C., Newley T.M.J. (1993) A Systematic Investigation into the most Suitable Data for the Development of Equations of State for Petroleum Reservoir Fluids, J. Fluid Phase Equilibria 82, 101-110.

Patel N., Teja A. (1982) A New Equation of State for Fluids and Fluid Mixtures, Chem. Eng. Sci. 37, 3, 463-473.

Pedersen K.S., Thomassen P., Fredenslund A. (1989) The Properties of Oils and Natural Gases, Gulf Publishing, Houston.

Pedersen K.S., Thomassen P., Fredenslund A. (1982) Phase equilibria and separation processes, Report SEP 8207, Inst.for Kemiteknik, Denmark Tekniske Hojskole.

Peneloux A., Rausy E., Freze R. (1982) A Consistent Correction for Redlich-Kwong-Soave Volumes, J. Fluid Phase Equilibria 8, 7-23. Redlich O., Kwong J. (1949) On the Thermodynamics of SolutionsAn Equation of State-Fugacities of Gaseous Solutions, Chem. Rev. 44, 233-247.

Riazi M.R. (1997) A Continuous Model for $\mathrm{C}_{7+}$ Fraction Characterization of Petroleum Fluids, Ind. Eng. Chem. Res. 36, 10, 4299-4307.

Riazi M.R., Daubert T.E. (1987) Characterizing Parameters for Petroleum Fractions, Ind. Eng. Chem. Res. 26, 24, 755-759.

Robinson D.B., Peng D. (1976) A New Two-Constant Equation of State, Ind. Eng. Chem. Fund. 19, 1, 59-64.

Schmidt G., Wenzel H. (1980) A Modified Van Der Waals Type Equation of State, Chem. Eng. Sci. 135, 1503-1512.

Sim W.J., Daubert T.E. (1980) Prediction of Vapor-Liquid Equilibria of Undefined Mixtures, Ind. Eng. Chem. Process Des. Dev. 19, 3, 380-393.

Slot-Peterson C. (1987) A Systematic and Consistent Approach to Determine Binary Interaction Coefficients for the Peng-Robinson Equation of State, SPE paper 16941, 62nd SPE Annual Technical Conference, Dallas, USA, 27-30.

Soave G. (1972) Equilibrium Constants from a Modified RedlichKwong Equation of State, Chem. Eng. Sci. 27, 1197-1203.

Whitson C.H., Anderson T.F., Soreide I. (1988) C7 ${ }^{+}$Characterization of Related Equilibrium Fluids Using the Gamma Distribution, AIChE Spring Meeting, New Orleans, USA, March 6-10.

Xu D., Danesh A., Todd A.C. (1992) An Accelerated Successive Substitution Method for Calculation of Multi-Component Fluids, Fluid Phase Equilibria 72, 15-24.

Final manuscript received in January 2011 Published online in September 2011

Copyright (C) 2011 IFP Energies nouvelles

Permission to make digital or hard copies of part or all of this work for personal or classroom use is granted without fee provided that copies are not made or distributed for profit or commercial advantage and that copies bear this notice and the full citation on the first page. Copyrights for components of this work owned by others than IFP Energies nouvelles must be honored. Abstracting with credit is permitted. To copy otherwise, to republish, to post on servers, or to redistribute to lists, requires prior specific permission and/or a fee: Request permission from Information Mission, IFP Energies nouvelles, fax. +33147527096 , or revueogst@ifpen.fr. 